\title{
Biocompatibility Assessment of Poly(lactic acid) Films after Sterilization with Ethylene Oxide in Histological Study In Vivo with Wistar Rats and Cellular Adhesion of Fibroblasts In Vitro
}

\author{
Michele Savaris, ${ }^{1}$ Gustavo L. Braga, ${ }^{2}$ Venina dos Santos, ${ }^{1}$ \\ Glaucio A. Carvalho, ${ }^{1}$ Asdrubal Falavigna, ${ }^{2}$ Denise C. Machado, ${ }^{3}$ \\ Christian Viezzer, ${ }^{3}$ and Rosmary N. Brandalise ${ }^{1}$ \\ ${ }^{1}$ Exact Sciences and Technology Center, Universidade de Caxias do Sul, 1130 Francisco Getúlio Vargas Street, \\ 95070-560 Caxias do Sul, RS, Brazil \\ ${ }^{2}$ Biological and Health Sciences Center, Universidade de Caxias do Sul, 1130 Francisco Getúlio Vargas Street, \\ 95070-560 Caxias do Sul, RS, Brazil \\ ${ }^{3}$ Biomedical Research Institute, Pontifícia Universidade Católica do Rio Grande do Sul, 6681 Ipiranga Avenue, \\ 90619-900 Porto Alegre, RS, Brazil
}

Correspondence should be addressed to Rosmary N. Brandalise; rnbranda@ucs.br

Received 30 January 2017; Revised 20 March 2017; Accepted 27 March 2017; Published 18 April 2017

Academic Editor: Debora Puglia

Copyright (C) 2017 Michele Savaris et al. This is an open access article distributed under the Creative Commons Attribution License, which permits unrestricted use, distribution, and reproduction in any medium, provided the original work is properly cited.

\begin{abstract}
Biomaterials must meet certain fundamental requirements for their usage in living beings, such as biocompatibility, bifunctionality, and sterilizability, without having chemical and structural changes. The biocompatibility of poly(lactic acid) (PLA) films, shaped by compression, was evaluated after sterilization by ethylene oxide by a histological in vivo test with Wistar rats and cytotoxicity in cell adhesion in vitro. The cytotoxicity test was performed by the reduction of tetrazolium salt (MTT). Thermal and chemical changes in PLA films concerning the proposed sterilization process and characteristics were not observed to evidence polymer degradation due to sterilization. The analysis of the cytotoxicity by the MTT method has shown that the sterilized PLA films are not cytotoxic. The adhesion and proliferation of fibroblasts on PLA films were homogeneously distributed over the evaluation period, showing an elongated appearance with unnumbered cytoplasmic extensions and cell-cell interactions. By examining the biocompatibility in a histological study, a mild tissue inflammation was observed with the presence of fibrosis in the samples that had been exposed for 21 days in the rats' bodies. PLA films sterilized with ethylene oxide did not exhibit cell adhesion in vitro and toxicity to the surrounding tissue in vivo and they may be used in future in vivo testing, according to histological findings in Wistar rats in the present study.
\end{abstract}

\section{Introduction}

Biomaterials must meet some basic requirements for use in human beings, such as being biocompatible, having no harmful effects on the locale, having biofunctionality, presenting adequate mechanical characteristics to meet the desired function for the time required, and being sterilizable, without chemical and thermal changes in the material [1-3].

Sterilization is one of the most important requirements for the use of biomaterials in human beings, since it proposes the elimination of the microorganisms present in the material, thus avoiding adverse effects associated with the use of biomaterials. Currently, there are several physical and chemical methods of sterilization, each with advantages and disadvantages depending on the material used [4].

Most polymeric biomaterials have relatively low fusion temperatures and are susceptible to degradation and/or morphological degeneration at high temperatures; this precludes the use of sterilization methods that require high temperatures [5]. 
One of the most used methods to sterilize polymeric materials is by ethylene oxide (EtO), given its excellent antimicrobial activity [6, 7]. However, the employment of this method has the disadvantage of unleashing adverse effects upon living organisms ranging from skin irritation to gastrointestinal disorders, central nervous system depression, neurological and cognitive impairment, hematological disorders, increasing risk of spontaneous miscarriage, and various types of cancer, in case of chronic exposure [8]. EtO is used for polymers' sterilization, but when the dimensions are very small, its use should be avoided due to difficulty in removing toxic waste in the residual sterilized material $[7,8]$. For this reason, the American agency "Food and Drug Administration" (FDA, 1978) [9] recommends that the concentration of ethylene oxide not exceed $250 \mathrm{ppm}$ for materials with a ratio of approximately $10 \mathrm{~g}$.

The poly(lactic acid) (PLA) used in this study is a biomaterial used in biodegradable sutures, as a matrix for drug release, biodegradable implants, and orthopedic support for tissue growth (scaffolds) [2, 10-12] due to the fact that it is bioresorbable and innocuous. PLA is a biodegradable polyester obtained by polymerization of lactic acid. Lactic acid is a chiral molecule which is present in stereoisomeric forms D and L. Metabolism of L-lactic acid occurs in all animals and microorganisms and does not exhibit toxic degradation products [13].

For biomedical applications, the process of in vitro degradation of PLA is influenced by factors such as molecular weight, crystalline fraction, dextrorotation, presence of comonomers, exposure time, concentration, temperature, $\mathrm{pH}$, porosity, dimensions, and other variables which influence the diffusion of water and EtO. In the in vivo system, the implant site determines the increase or decrease of polymer degradation rate. All of these parameters can modify the PLA degradation and hence the rate of release of lactic acid which influences the cytotoxicity of the implants in vivo $[14,15]$.

Beyond the in vitro processes, the sterilization, as mentioned before, also has influence upon biological, chemical, thermal, and mechanical properties of biomaterials, as well as biocompatibility. Faced with facts, it has become fundamental to understand the interactions and reactions that happen between material and tissue.

Aiming to progressively increase the research in the biomaterial sector and the processes that are submitted to this type of material and what they can bring to human beings, this pilot study pursues the evaluation of sterilization by ethylene oxide and its consequences in PLA properties, as well as its histological evaluation and biocompatibility.

\section{Materials and Methods}

The poly(DL-lactic acid) used is of medical grade, PURASORB brand, manufactured by the Dutch company Purac, being encoded in this study as PLA.

The experimental group of rats for the preliminary study of biocompatibility comprised 5 Wistar female rats, 5-6 weeks of age (young adults), with a body weight between 300 and $350 \mathrm{~g}$. The number of rats used in this study is reduced; however, it is a minimal amount that allows representative results to be obtained for the preliminary study proposal in this study. The animals were obtained from Fundação de Apoio Universitário (FAU) and Fundação Universidade do Rio Grande (FURG).

The tetrazolium salt 3-(4,5-dimethylthiazol-2-yl)-2,5diphenyl tetrazolium bromide (MTT) (Sigma-Aldrich) was used for the cytotoxicity test. The following culture media were used: Dulbecco's modified Eagle's medium (DMEM) (Gibco Invitrogen Corporation), gentamicin (Gibco) from Novafarma; streptomycin/penicillin (Gibco) from Aché, supplemented with $10 \%$ fetal bovine serum (FBS) (Gibco), mouse fibroblast NIH-3T3 cells by American Type Culture Collection (ATCC CRL-1658), methanol > 99\% purity (Telemetrics Inc.), amoxicillin/clavulanate (GSK), xylazine and ketamine (Vet Brands), mononylon 3.0 (Point Suture), tramadol (generic Legrand), formaldehyde (Coremal), and hematoxylin-eosin (Merck).

PLA films were obtained by compression molding in equipment, Schulz brand, model PHS 15T, at the temperature of $170^{\circ} \mathrm{C}$ for 5 minutes.

The thermal properties of the films were measured before and after the sterilization process by means of thermogravimetry (TGA) on TGA equipment Shimadzu brand TGA-50 (Japan), with a heating rate of $10^{\circ} \mathrm{C} \cdot \mathrm{min}^{-1}$, with inert $\mathrm{N}_{2}$ atmosphere $\left(50 \mathrm{~mL} \cdot \mathrm{min}^{-1}\right)$ at temperatures of $20-800^{\circ} \mathrm{C}$ and by differential scanning calorimetry (DSC) on Shimadzu DSC-50 (Japan) equipment, using a heating rate of $10^{\circ} \mathrm{C} \cdot \mathrm{min}^{-1}$ and flow of $\mathrm{N}_{2}$ of $50 \mathrm{~mL} \cdot \mathrm{min}^{-1}$.

The chemical changes were monitored by Fourier transform infrared (FTIR) spectroscopy on equipment of the Thermo Scientific Nicolet brand IS10 (USA) in the range of $4000-550 \mathrm{~cm}^{-1}$ using attenuated total reflectance (ATR) mode, using diamond crystal.

The PLA films were sanitized with first washing with double purified water, followed by drying with sterile compressed air and then by a sonication process with enzymatic compounds seeking to improve detachment of possible residues. After hygienization, the PLA films were sterilized with ethylene oxide following the mechanical aeration process, hyperventilation, and natural aeration for 24 hours (in an accredited company in the city of Caxias do Sul, Brazil). The hygienization and sterilization parameters used in this study were also applied in other studies of the group $[16,17]$. According to the FDA (1978), aeration for $96 \mathrm{~h}$ at room temperature is recommended for all polymers, except for poly(vinyl chloride) (PVC). The enzymatic detergent used for hygienization was Endozime ${ }^{\circledR}$ AW Plus, which is composed by amylase, lipase, protease, and carbohydrase, with enhanced proteolytic action. Its function is to completely remove all organic material with corrosion inhibition. The composition also includes isopropyl alcohol, the group of amylases, proteases, lipases, carbohydrases enzymes, nonionic detergent dye, perfume, and water.

The cytotoxicity and cell adhesion tests were performed using cells of fibroblast NIH-3T3 rats (Pontifical Catholic University of Rio Grande do Sul, Porto Alegre, Brazil). Cells were grown in $75 \mathrm{~cm}^{2}$ flasks containing Dulbecco's modified 
Eagle's medium (DMEM), Dulbecco's growth medium, gentamicin $\left(0.025 \mathrm{~g} \cdot \mathrm{L}^{-1}\right)$, and streptomycin/penicillin $\left(0.1 \mathrm{~g} \cdot \mathrm{L}^{-1}\right)$ and supplemented with $10 \%$ fetal bovine serum (FBS) in a humidified atmosphere at $37^{\circ} \mathrm{C}$ with $5 \% \mathrm{CO}_{2}$. Cells had been grown to confluence and then used for evaluation.

The cytotoxicity assessment was done in accordance with the ISO 10993-5 evaluation of mitochondrial function by reduction of the tetrazolium salt MTT. Sample extracts were prepared in DMEM. PLA films $\left(3 \mathrm{~cm}^{2} \cdot \mathrm{mL}^{-1}\right)$, after sterilization with EtO, were placed in DMEM for 24, 48, and 72 hours and incubated in a humidified atmosphere at $37^{\circ} \mathrm{C}$ with $5 \% \mathrm{CO}_{2}$. Negative control with DMEM, as well as positive control $\left(0.1 \mathrm{~g} \cdot \mathrm{mL}^{-1}\right)$ of copper sulfate, was also included in the cytotoxicity tests. The suspension of NIH-3T3 cells had been adjusted and seeded at a density of $0.5 \times 10^{4}$ cells/well in 96well plates and incubated for 24 hours for adherence. From these samples, $50 \mu \mathrm{L}$ was extracted and incubated for 24 hours at $37^{\circ} \mathrm{C}$ with $5 \% \mathrm{CO}_{2}$. Right after the incubation, the growth medium in each well was removed and the wells were rinsed with phosphate buffered saline (PBS). Further, $10 \%$ of MTT solution $\left(5 \mathrm{mg} \cdot \mathrm{mL}^{-1}\right)$ in DMEM was added to each well and incubated for 4 hours. Finally, the medium was replaced with $100 \mu \mathrm{L}$ dimethyl sulfide (DMSO) to solubilize the crystals formed by the living cells. The absorbance was measured in a spectrophotometer (microplate reader, Bio-Rad) at $570 \mathrm{~nm}$. The absorbance values obtained were normalized against the negative control as $100 \%$ viable cells. All samples were produced in triplicate.

Cell adhesion was evaluated using PLA films with a $0.5 \mathrm{~cm}$ diameter. The films were placed in 6-well cell culture plates and NIH-3T3 cells were adjusted and seeded at 1.5 $\times 10^{4}$ cells in DMEM. After the culturing period of 24,48 , and 72 hours, the films containing the cells were washed in phosphate buffered saline (PBS) and fixed in methanol. Then, they were dyed with hematoxylin-eosin and observed under an optical microscope (OM) (Nikon) (Pontifical Catholic University of Rio Grande do Sul, Porto Alegre, Brazil) at 400x magnification.

Statistical analyses in the study for cell adhesion were performed using a one-way analysis of variance (ANOVA) (GraphPad Prism 6.0, GraphPad Software, Inc.) employing Dunnett's test to compare results of test cultures with those of the negative control. In all cases, the level of statistical significance was set at $p<0.05$. The results were expressed as mean \pm standard deviation of the mean $(n=3)$.

The preliminary histological study of the PLA films, in vivo, was performed on Wistar rats. It is recommended that laboratory animal care follow the guidelines of animal practices, such as the "Guiding Principles in the Care and Use of Animals for Scientific Purposes" (University of Caxias do Sul, Caxias do Sul, Brazil) [18-20].

The animals were properly secured in special individual cages and were housed in proper dormitories respecting the light-dark cycle of 12 hours (from 7:00 to 19:00). Temperature and humidity were kept between 23 and $26^{\circ} \mathrm{C}$ and 62 and $68 \%$, respectively, in a controlled environment. Feeding was performed with water and food for specific rats. Prophylaxis was made using antibiotics against bacterial infections 5 days before and 5 days after surgery, using $320 \mathrm{mg}$ of amoxicillin + potassium clavulanate in $500 \mathrm{~mL}$ of water that was available without restriction to the animals. The induction of anesthesia with $2 \%$ xylazine $\left(50 \mathrm{mg} \cdot \mathrm{kg}^{-1}\right.$ ) and $10 \%$ ketamine $\left(50 \mathrm{mg} \cdot \mathrm{kg}^{-1}\right)$ intraperitoneally was performed.

During surgery, when required, anesthesia was reapplied to $1 / 3$ of the induction dose. PLA films with dimensions of 1 $\times 1 \mathrm{~cm}$, previously sterilized, were placed subcutaneously in the rats for biocompatibility analysis. After anesthetizing the animals with ketamine and xylazine, two skin incisions were made, measuring approximately $1.5 \mathrm{~cm}$ each. An incision was made in the dorsal region (right side), while the other was on the left dorsal region of the second level and third vertebral body of the lower back. The PLA film was placed in the subcutaneous incision in the right side, with the suture being carried out with simple points with mononylon 3.0 for skin closure. On the left side, the same skin closure was performed without placing the material subcutaneously.

After the surgical procedure, an injection was performed by applying $0.7 \mathrm{~mL}$ of tramadol $0.5 \mathrm{mg} \cdot \mathrm{mL}^{-1}$ in the posterior cervical region as a single dose. The animals were placed in separate individual cages with food and water ad libitum until sacrifice.

The removal of subcutaneous PLA films of the mice was performed after 14, 21, and 28 days. The material in each drawing was washed with distilled water and dried in a desiccator for a period of 24 hours.

PLA film $(10 \times 10 \mathrm{~mm})$ was then removed and stored in a proper container for chemical and thermal analysis: DSC, TGA, and FTIR. Then, an excisional biopsy was made in the subcutaneous tissues and muscle adjacent to the incisions in the right hemiback (around the implant) and in the left hemiback, measuring approximately $1.5 \times 1.5 \mathrm{~cm}$. Tissue samples were placed in a container with a $10 \%$ formaldehyde solution for histological analysis. The analysis intended to assist in verifying the inflammatory tissue reaction triggered by the material. Each layer (subcutaneous and muscle) was placed in containers with different numbers, without revealing to the pathologist which dorsal area would be analyzed. The same procedure took place on the 21st and 28th days. The samples taken from the lab mice to perform biopsy were then tested for biocompatibility, submerged in phosphate buffered saline (PBS), fixed with $4 \%$ formaldehyde in PBS, dehydrated in alcohol, embedded in paraffin, sectioned in slices of $4 \mu \mathrm{m}$, and stained with hematoxylin-eosin. At least three serial slices of each block were analyzed independently by two experts using optical microscopy, in search of a cellular inflammatory response and for assessing the thickness of the fibrotic capsule around the material. The extent of the inflammatory response was quantified by the presence of inflammatory cells (polymorph nuclear leukocytes, lymphocytes, macrophages, and foreign body giant cells), fibrin, exudates, necrosis, and vascularization [21]. The presence of inflammatory markers was graded from 0 (absent) to 3 (abundant). The thickness of the peri-implant fibrotic capsule was defined as the gap between the edge of the adjacent fibrous tissue and the muscle or the adipose tissue adjacent to the fibrotic capsule $[22,23]$. 


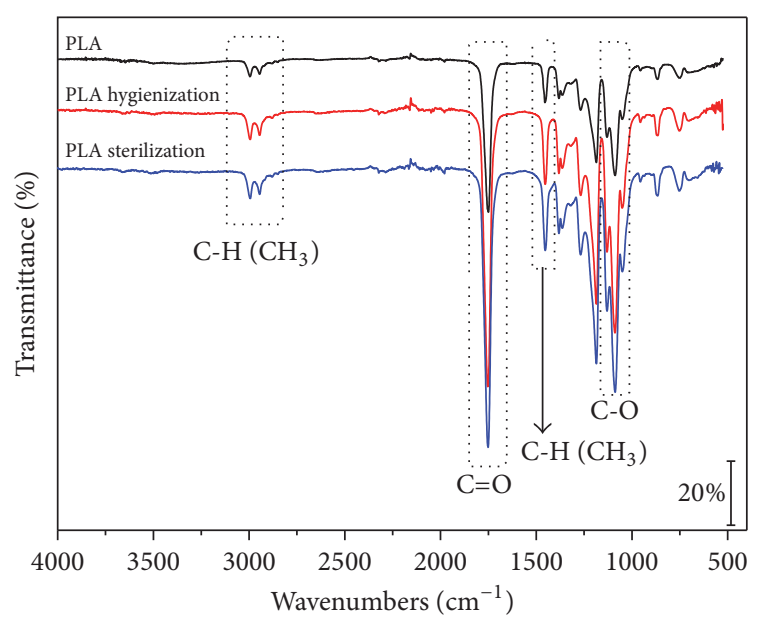

FIGURE 1: FTIR of PLA before and after the hygienization and sterilization process.

\section{Results and Discussion}

In this study, the following code has been used to identify the samples: PLA (PLA); PLA after hygienization process (PLA hyg.); PLA after hygienization and sterilization processes (PLA ste.); PLA after hygienization and sterilization processes, not used in implant (PLA, 0 days); PLA after hygienization and sterilization processes after 14 days of in vivo exposure (PLA, 14 days); PLA after hygienization and sterilization processes after 21 days of in vivo exposure (PLA, 21 days); PLA after hygienization and sterilization processes after 28 days of in vivo exposure (PLA 28, days).

Figure 1 shows the infrared spectra of the PLA before and after the hygienization and sterilization process. The characteristic bands of PLA are at $2995-2945 \mathrm{~cm}^{-1}$ related to the $\mathrm{C}-\mathrm{H}$ stretching $\left(\mathrm{CH}_{3}\right)$, at $1748 \mathrm{~cm}^{-1}$ related to the stretching of $\mathrm{C}=\mathrm{O}$, at $1453 \mathrm{~cm}^{-1}$ attributed to deformation $\mathrm{CH}_{3}$ group, and at $1181 \mathrm{~cm}^{-1}$ related to the symmetrical stretching of CO, and three bands at 1128, 1082, and $1043 \mathrm{~cm}^{-1}$ are related to the symmetrical stretching of C-O-C; the PLA characteristic bands are in agreement with the literature $[24,25]$. The absence of a broad band and high intensity in the region of $3500-3000 \mathrm{~cm}^{-1}$ (OH stretch characteristic of the carboxylic acid) indicates the absence of PLA hydrolysis products (lactic acid and/or pyruvic acid) [26]. As the PLA is a polyester, hydrolysis of by-products would be expected, due to the heat treatment resulting in the production of films and to hygienization and sterilization; instead, the infrared spectra showed no bands that could be attributed to degradation products of PLA (by hydrolysis), both before and after the hygienization and sterilization processes, which shows that the hygienization and sterilization processes did not promote the degradation of the PLA.

In FTIR analysis of PLA samples after implantation in rats with different exposure times (Figure 2), one can observe the appearance of a band (from 14 days after exposure), although it is of lower intensity in the region $3200 \mathrm{~cm}^{-1}$ due to hydrolysis of the films. Every material implanted in vivo

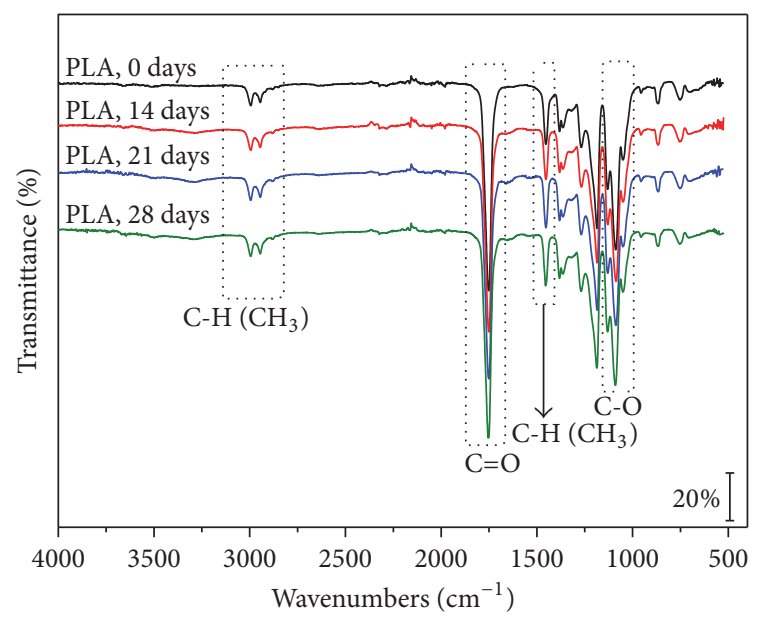

FIGURE 2: FTIR spectrum of PLA samples with different times of exposure in the animal body.

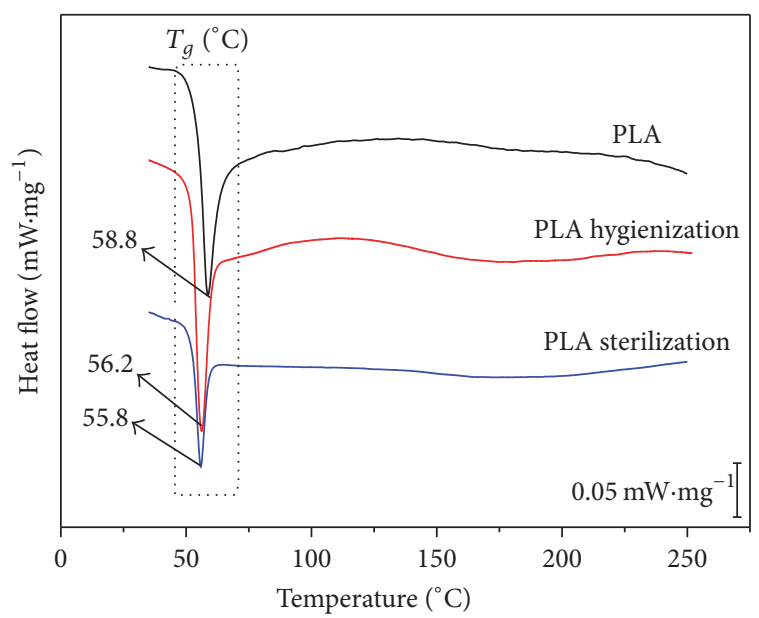

FIGURE 3: DSC thermograms of the PLA before and after the hygienization and sterilization process.

has been affected by the surrounding environment. Water is the main component of body fluids and directly influences the degradation mechanism [27].

In DSC analysis, only the first heating run was performed for each sample because the aim of this study was to evaluate the behavior of the treatments and periods in vivo under PLA. Such effects could not be observed in the second heating event, due to destruction of thermal history of the material.

The thermal characteristics of PLA in the DSC are shown in Figure 3 before and after the hygienization and sterilization process.

The poly(DL-lactic acid) is amorphous, while the poly $(\mathrm{L}$ lactic acid) and poly(D-lactic acid) are semicrystalline. The glass transition temperature $\left(T_{g}\right)$ is within the range of 50 to $80^{\circ} \mathrm{C}$ while the melting temperature $\left(T_{m}\right)$ can vary from 130 to $180^{\circ} \mathrm{C}$ [24].

It was found that the sterilization process had caused a shift to lower temperatures of $T_{g}$, attributed to the absorption 


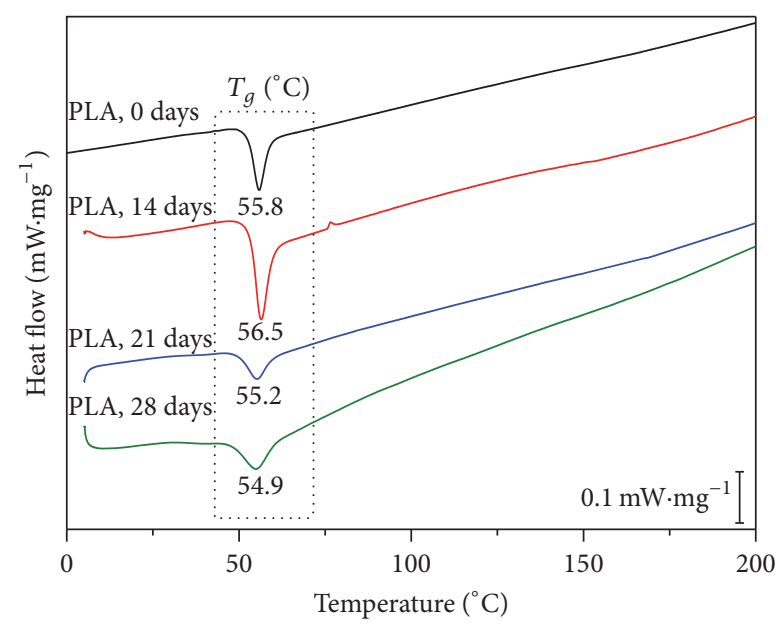

FIgURE 4: DSC thermograms of the PLA samples with different in vivo exposure times.

of water by the PLA in the hygienization and sterilization process.

Figure 4 shows the DSC thermograms and the $T_{g}$ values of the PLA films after implantation in rats.

A reduction of PLA chains order was observed in the in vitro transaction with the increase of the period of implementation in the mice. This process consists in a better organization of the polymeric chains of amorphous phase, due to PLA's thermal history.

The PLA presented a glass transition $\left(T_{g}\right)$ at $55.8^{\circ} \mathrm{C}$, with a tendency to move towards lower temperatures. This can be attributed to degradation of the amorphous regions of the polymer by hydrolysis; the structures showed mobility at lower temperatures because of chain scission $[28,29]$, the most obvious shift after 28 days of exposure of the polymer to the animal organism. The absorption and hydrolysis processes when tested in vivo favored the degradation of the PLA [30, 31].

Figure 5 shows the thermograms of samples before and after the hygienization and sterilization process when only one mass loss event has been observed in both samples.

The hygienization and sterilization processes promoted a decrease in the maximum degradation temperature in the event of mass loss around the temperature of $360^{\circ} \mathrm{C}$. It is suspected that this difference in behavior is related to hygienization and sterilization procedures with ethylene oxide and the drying process at $80^{\circ} \mathrm{C}$ for $60 \mathrm{~min}$, conventionally used for the treatment of mechanical aeration, hyperventilation, and natural aeration for $24 \mathrm{~h}$. The FDA (1978) recommends $96 \mathrm{~h}$.

TGA thermograms of PLA samples after implantation in rats with different times of exposure to the biological fluid (Figure 6) revealed that the sample remaining in the rat body for 28 days showed a significant decrease in PLA degradation temperature (maximum), due to the start of the process of biosorption and hydrolysis that favored the degradation of PLA.

Cytotoxicity analysis in NIH-3T3 cells with polymer extracts allows an evaluation of the ability of viable cells to

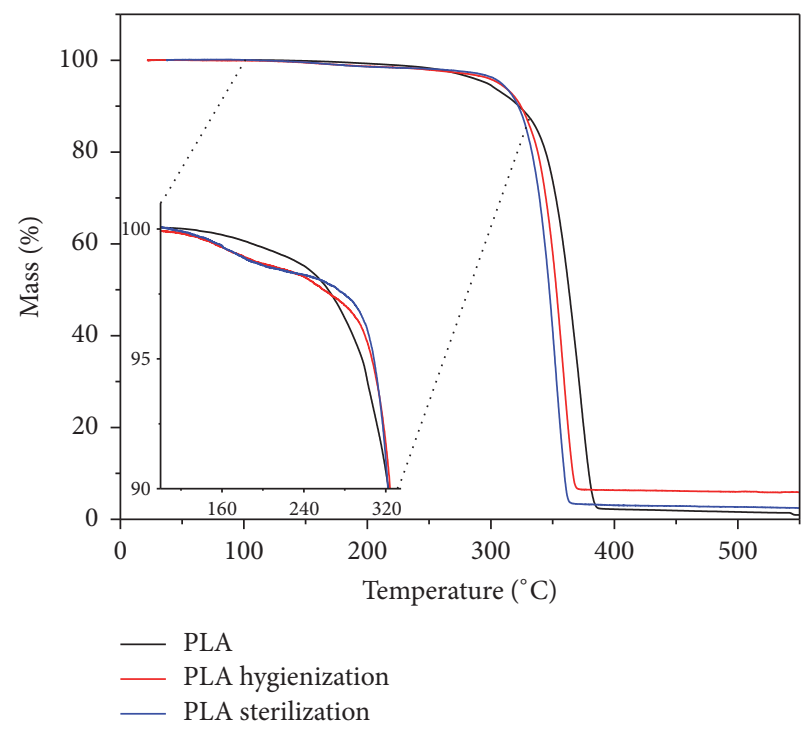

FIgURE 5: TGA thermogram of the PLA before and after the hygienization and sterilization process.

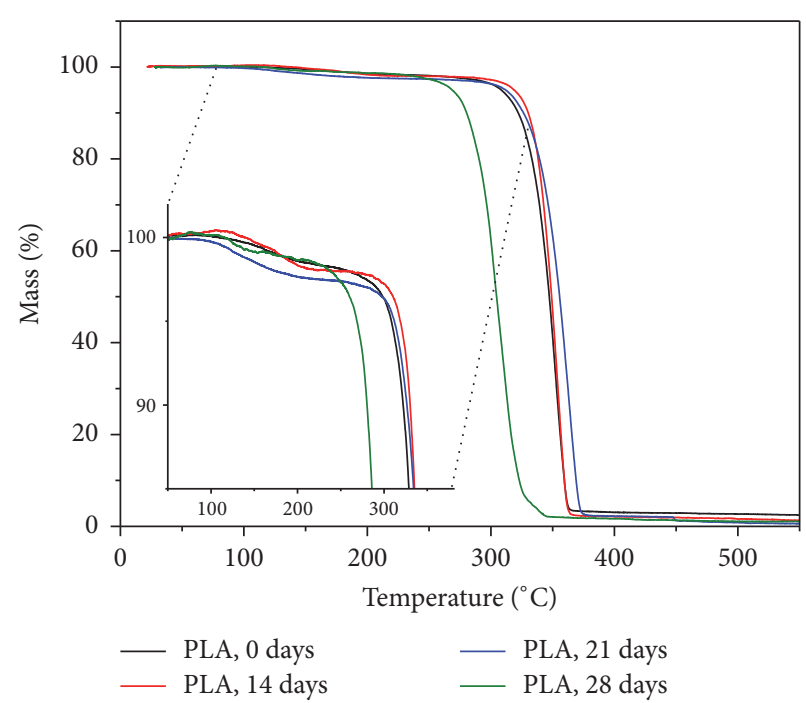

Figure 6: TGA thermograms of the PLA samples with different in vivo exposure times.

reduce the tetrazolium salt into formazan via mitochondrial metabolic activity. Absorbance values measured considering formazan salt reduction are directly related to cell viability $[32,33]$.

Table 1 shows the average percentage of cell viability at different times of culture with the polymer extract.

The results indicated that the extracts of the material compared to the negative and positive controls have not presented significant cytotoxicity (Table 1 ). We observed at exposure time of 24 hours less cell viability $(74 \pm 13 \%)$ when compared to other periods, up to $100 \%[34,35]$. This could be due to a residual concentration of EtO present in the PLA after sterilization which could be diffused in the DMEM in 


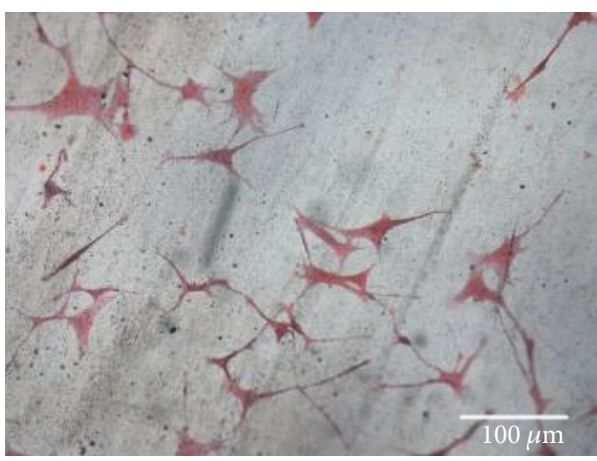

(a)

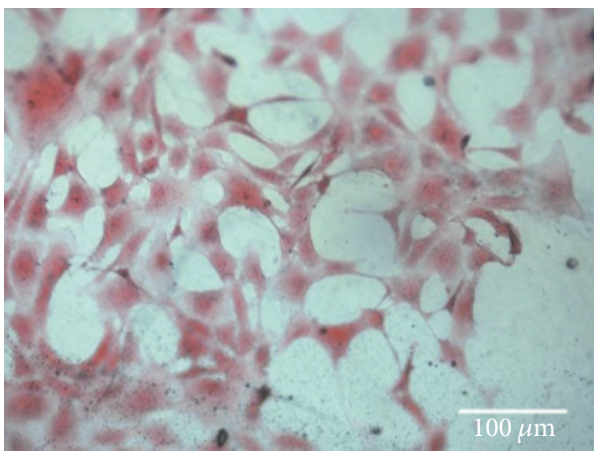

(c)

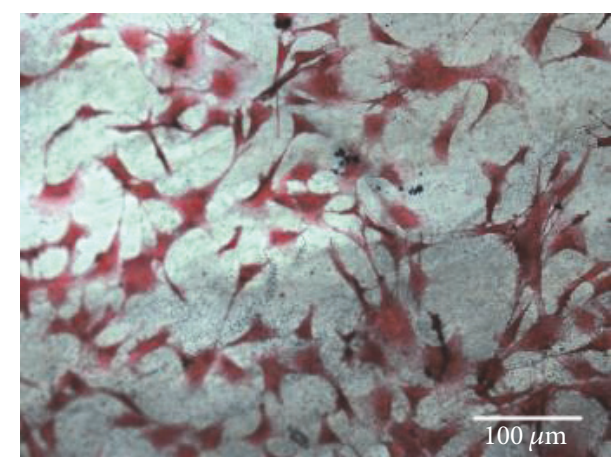

(b)

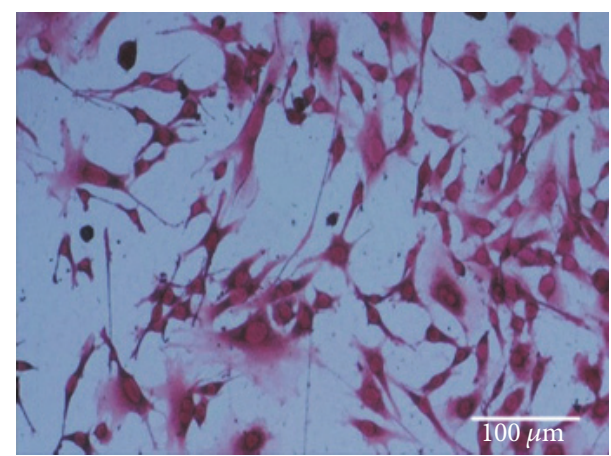

(d)

FIgURE 7: NIH-3T3 cells culture on PLA films at (a) 24 hours, (b) 48 hours, and (c) 72 hours and (d) control culture plate (400x magnification; bar: $100 \mu \mathrm{m})$.

TABLE 1: Mean values and standard deviation of cell viability percentage for periods of 24,48 , and 72 hours $\left({ }^{*} p<0.0001\right.$; NC: negative control; PC: positive control).

\begin{tabular}{lccc}
\hline \multicolumn{4}{c}{ Incubation periods (hours) } \\
Group & $24 \mathrm{~h}$ & $48 \mathrm{~h}$ & $72 \mathrm{~h}$ \\
\hline PLA & $74 \pm 13 \%$ & $118 \pm 21 \%$ & $118 \pm 14 \%$ \\
\hline NC & & $100 \pm 13 \%$ & \\
PC & & $11 \pm 0.5 \%{ }^{*}$ & \\
\hline
\end{tabular}

the first 24 hours of extraction leading to an enhancement of cytotoxicity compared to other extraction times.

Figure 7 shows the progress of adhesion and cell proliferation evaluated on the membrane in the time period evaluated.

The cells (mice fibroblast cells NIH-3T3) have a similar morphology to the homogeneously distributed positive control cells, with elongated appearance and numerous cytoplasmic extensions and cell-to-cell interactions $[36,37]$. Cell proliferation was not evaluated in this study; however, it was noticeable that cells that adhered onto PLA films have shown an increasing proliferation trend with their respective time in culture, that is, greater number of cells in the longer periods in growth medium.

After polymer removal of the rat skin on days 14, 21, and 28 , the material was washed with distilled water and dried in a desiccator for 24 hours. The morphology of the samples was analyzed by OM (Nikon) at 200x magnification (Figure 8).

The remaining sample in the body of animals for 28 days had a milky white color, losing the original transparency, when compared with the starting sample and the sample after 14 days. Changes in PLA film color from transparent to matte (whitish) were also observed in another study of the group by colorimetric analysis [17]. According to Fukushima et al. [38], this change of color is assigned to PLA degradation, which changes the refractive index of the sample, which occurs as a consequence of water absorption and/or the presence of products resulting from the hydrolysis process.

Table 2 shows the results obtained after the histology analysis of the tissue surface and deeper tissues throughout the experiment, categorizing the analysis of the number of weeks after surgery and also recording the number of samples that have shown no inflammation or soft inflammation.

There was an increase in the number of samples that showed mild inflammation in the side where the polymer had been implemented, which should be expected after insertion of a foreign body. There was also an increase in the inflammatory response and fibrosis after the third week, in the deep tissue of the left side. Despite higher prevalence of inflammatory reaction in the samples featuring the polymer, there was a very low prevalence and probably there will not be interference with future tests. 


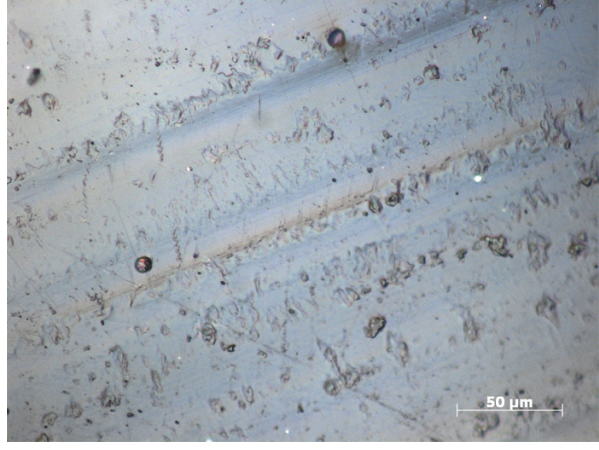

(a)

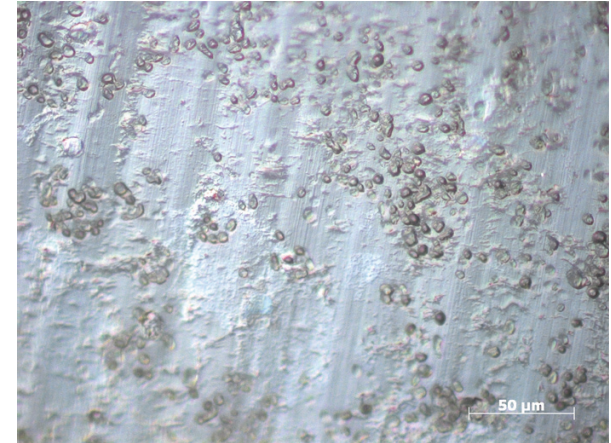

(b)

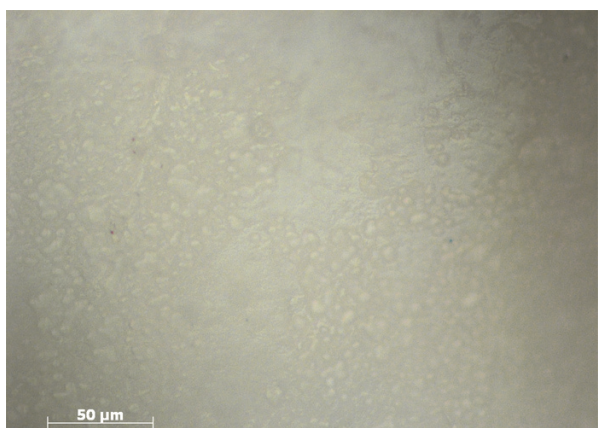

(c)

Figure 8: Micrographs (OM) of the samples: (a) PLA; (b) PLA, 14 days; (c) PLA, 28 days of in vivo testing.

TABLE 2: Results of histological analysis of surface tissue for the three periods of exposure.

\begin{tabular}{lcc}
\hline & $\begin{array}{c}\text { Without inflammation } \\
\text { Number of rats } \\
(\%)\end{array}$ & $\begin{array}{c}\text { Mild inflammation } \\
\text { Number of rats } \\
(\%)\end{array}$ \\
\hline $\begin{array}{l}\text { Superficial tissue } \\
\text { With polymer }\end{array}$ & $2(40)$ & $3(60)$ \\
Without polymer & $5(100)$ & $0(0)$ \\
Deep tissue & & $3(60)$ \\
With polymer & $2(40)$ & $0(0)$ \\
Without polymer & $5(100)$ & \\
Days after surgery & & $1(25)$ \\
(left dorsal area) & & $2(50)$ \\
14 & $3(75)$ & $1(50)$ \\
21 & $2(50)$ & \\
28 & $1(50)$ & \\
\hline
\end{tabular}

\section{Conclusion}

In this study, PLA films underwent hygienization and sterilization with ethylene oxide. Chemical changes were not observed in the procedure for hygienization and sterilization of PLA samples, indicating that the polymer did not show evidence of deterioration due to treatments under natural aeration. Changes in thermal properties indicated the occurrence of characteristic processes of PLA such as water absorption, hydrolysis, and change in color of the PLA sample that was extracted after 28 days of in vivo tests, indicating the beginning of the process of bioresorption. The extracts analysis of the polymer showed good biocompatibility in vitro, where the mitochondrial activity was assessed as well as the proliferation of cells in polymer films during the studied periods and up to 72 hours. The conditions of sterilization and hygiene proposed in this study for PLA films and changes in their properties because of such processes have not inhibited cell growth in vitro and have allowed the use of this polymer in vivo.

\section{Conflicts of Interest}

The authors declare that they have no conflicts of interest.

\section{Acknowledgments}

The authors thank CNPq for the financial support.

\section{References}

[1] B. D. Ratner, A. S. Hoffman, F. J. Schoen, and J. E. Lemons, Biomaterials Science: An Introduction to Materials in Medicine, Inglaterra: Elsevier, London, UK, 2nd edition, 2004.

[2] S. Bauer, P. Schmuki, K. von der Mark, and J. Park, "Engineering biocompatible implant surfaces. Part I: materials and surfaces," Progress in Materials Science, vol. 58, pp. 261-326, 2013.

[3] L. L. Hench, "Biomaterials: a forecast for the future," Biomaterials, vol. 19, no. 16, pp. 1419-1423, 1998. 
[4] W. A. Rutala and D. J. Weber, "Clinical effectiveness of lowtemperature sterilization technologies," Infection Control and Hospital Epidemiology, vol. 19, no. 10, pp. 798-804, 1998.

[5] S. Hofmann, K. S. Stok, T. Kohler, A. J. Meinel, and R. Müller, "Effect of sterilization on structural and material properties of 3-D silk fibroin scaffolds," Acta Biomaterialia, vol. 10, no. 1, pp. 308-317, 2014.

[6] W. A. Rutala, M. F. Gergen, and D. J. Weber, "Comparative evaluation of the sporicidal activity of new low-temperature sterilization technologies: ethylene oxide, 2 plasma sterilization systems, and liquid peracetic acid," American Journal of Infection Control, vol. 26, no. 4, pp. 393-398, 1998.

[7] M. J. Alfa, P. DeGagne, N. Olson, and R. Hizon, "Comparison of liquid chemical sterilization with peracetic acid and ethylene oxide sterilization for long narrow lumens," American Journal of Infection Control, vol. 26, no. 5, pp. 469-477, 1998.

[8] G. C. C. Mendes, T. R. S. Brandão, and C. L. M. Silva, "Ethylene oxide sterilization of medical devices: a review," American Journal of Infection Control, vol. 35, no. 9, pp. 574-581, 2007.

[9] Department of Health; Education and Welfare; Food and Drug Administration (FDA), Ethylene oxide, ethylene chlorohydrin, and ethylene glycol, 1978.

[10] C. M. Patist, M. B. Mulder, S. E. Gautier, V. Maquet, R. Jérôme, and M. Oudega, "Freeze-dried poly(D,L-lactic acid) macroporous guidance scaffolds impregnated with brain-derived neurotrophic factor in the transected adult rat thoracic spinal cord," Biomaterials, vol. 25, no. 9, pp. 1569-1582, 2004.

[11] B. Gupta, N. Revagade, and J. Hilborn, "Poly(lactic acid) fiber: an overview," Progress in Polymer Science, vol. 32, no. 4, pp. 455482, 2007.

[12] R. M. Rasal, A. V. Janorkar, and D. E. Hirt, "Poly(lactic acid) modifications," Progress in Polymer Science, vol. 35, no. 3, pp. 338-356, 2010.

[13] H. R. Kricheldorf, "Syntheses and application of polylactides," Chemosphere, vol. 43, no. 1, pp. 49-54, 2001.

[14] F. W. Cordewener, M. F. Van Geffen, C. A. P. Joziasse et al., "Cytotoxicity of poly(96L/4D-lactide): the influence of degradation and sterilization," Biomaterials, vol. 21, no. 23, pp. 2433-2442, 2000.

[15] R. De Tayrac, S. Chentouf, H. Garreau et al., "In vitro degradation and in vivo biocompatibility of poly(lactic acid) mesh for soft tissue reinforcement in vaginal surgery," Journal of Biomedical Materials Research - Part B Applied Biomaterials, vol. 85, no. 2, pp. 529-536, 2008.

[16] M. Savaris, G. A. Carvalho, A. Falavigna, V. Dos Santos, and R. N. Brandalise, "Chemical and thermal evaluation of commercial and medical Grade PEEK sterilization by Ethylene oxide," Materials Research, vol. 19, no. 4, pp. 807-811, 2016.

[17] M. Savaris, V. D. Santos, and R. N. Brandalise, "Influence of different sterilization processes on the properties of commercial poly(lactic acid)," Materials Science and Engineering C, vol. 69, pp. 661-667, 2016.

[18] National Research Council, Guide for the Care and Use of Laboratory Animals, The National Academies Press, Washington, DC, USA, 8th edition, 2011.

[19] A. Falavigna, F. Cechetti, G. Finger, L. G. Ruschel, G. Marcon, and P. G. Da Silva, "Experimental model of spinal cord injury (SCI) in rats: management guidelines," Coluna/Columna, vol. 12, no. 1, pp. 70-72, 2013.

[20] V. Kumar, N. Fausto, A. Abbas, S. L. Robbins, and N. Cotran, Pathologic Basis of Disease, WB Saunders/Elsevier, Philadelphia, $\mathrm{Pa}, \mathrm{USA}, 7$ th edition, 2005.
[21] G. W. Bos, W. E. Hennink, L. A. Brouwer et al., "Tissue reactions of in situ formed dextran hydrogels crosslinked by stereocomplex formation after subcutaneous implantation in rats," Biomaterials, vol. 26, no. 18, pp. 3901-3909, 2005.

[22] A. K. Azab, V. Doviner, B. Orkin et al., "Biocompatibility evaluation of crosslinked chitosan hydrogels after subcutaneous and intraperitoneal implantation in the rat," Journal of Biomedical Materials Research. Part A, vol. 83, no. 2, pp. 414-422, 2007.

[23] W. S. Drumond, S. H. Wang, and C. G. Mothé, "Síntese e caracterização do copolímero poli (ácido lático-b-glicol etilênico)," Polímeros, vol. 14, no. 2, pp. 74-79, 2004.

[24] L. Qin, J. Qiu, M. Liu et al., "Mechanical and thermal properties of poly(lactic acid) composites with rice straw fiber modified by poly(butyl acrylate)," Chemical Engineering Journal, vol. 166, no. 2, pp. 772-778, 2011.

[25] C.-C. Chen, J.-Y. Chueh, H. Tseng, H.-M. Huang, and S.-Y. Lee, "Preparation and characterization of biodegradable PLA polymeric blends," Biomaterials, vol. 24, no. 7, pp. 1167-1173, 2003.

[26] L. De Vuyst and B. Degeest, "Heteropolysaccharides from lactic acid bacteria," FEMS Microbiology Reviews, vol. 23, no. 2, pp. 153-177, 1999.

[27] J. Brzeska, A. Heimowska, W. Sikorska, L. Jasińska-Walc, M. Kowalczuk, and M. Rutkowska, "Chemical and enzymatic hydrolysis of polyurethane/polylactide blends," International Journal of Polymer Science, vol. 2015, Article ID 795985, 8 pages, 2015.

[28] Y. Wang, J. Pan, X. Han, C. Sinka, and L. Ding, "A phenomenological model for the degradation of biodegradable polymers," Biomaterials, vol. 29, no. 23, pp. 3393-3401, 2008.

[29] V. D. Jahno, G. B. M. Ribeiro, L. A. Dos Santos et al., "Chemical synthesis and in vitro biocompatibility tests of poly (L-lactic acid)," Journal of Biomedical Materials Research. Part A, vol. 83, no. 1, pp. 209-215, 2007.

[30] K. F. Bombonato-Prado, M. R. Wimmers Ferreira, A. L. Rosa et al., "Human alveolar bone-derived cell-culture behaviour on biodegradable poly(L-lactic acid)," Journal of Biomaterials Science, Polymer Edition, vol. 20, no. 2, pp. 167-179, 2009.

[31] M. E. Gomes, R. L. Reis, A. M. Cunha, C. A. Blitterswijk, and J. D. De Bruijn, "Cytocompatibility and response of osteoblasticlike cells to starch-based polymers: effect of several additives and processing conditions," Biomaterials, vol. 22, no. 13, pp. 1911-1917, 2001.

[32] E. Briganti, P. Losi, A. Raffi, M. Scoccianti, A. Munaò, and G. Soldani, "Silicone based polyurethane materials: a promising biocompatible elastomeric formulation for cardiovascular applications," Journal of Materials Science: Materials in Medicine, vol. 17, no. 3, pp. 259-266, 2006.

[33] A. van Sliedregt, J. A. van Loon, J. van der Brink, K. de Groot, and C. A. van Blitterswijk, "Evaluation of polylactide monomers in an in vitro biocompatibility assay," Biomaterials, vol. 15, no. 4, pp. 251-256, 1994.

[34] T. Almeida, B. J. M. Leite Ferreira, J. Loureiro, R. N. Correia, and C. Santos, "Preliminary evaluation of the in vitro cytotoxicity of PMMA-co-EHA bone cement," Materials Science and Engineering $C$, vol. 31, no. 3, pp. 658-662, 2011.

[35] A. N. Hayati, S. M. Hosseinalipour, H. R. Rezaie, and M. A. Shokrgozar, "Characterization of poly(3hydroxybutyrate)/nano-hydroxyapatite composite scaffolds fabricated without the use of organic solvents for bone tissue engineering applications," Materials Science and Engineering C, vol. 32, no. 3, pp. 416-422, 2012. 
[36] S. Lakard, G. Herlem, A. Propper et al., "Adhesion and proliferation of cells on new polymers modified biomaterials," Bioelectrochemistry, vol. 62, no. 1, pp. 19-27, 2004.

[37] Z. Oezyuerek, K. Franke, M. Nitschke et al., "Sulfated glycoblock copolymers with specific receptor and growth factor binding to support cell adhesion and proliferation," Biomaterials, vol. 30, no. 6, pp. 1026-1035, 2009.

[38] K. Fukushima, C. Abbate, D. Tabuani, M. Gennari, and G. Camino, "Biodegradation of poly(lactic acid) and its nanocomposites," Polymer Degradation and Stability, vol. 94, no. 10, pp. 1646-1655, 2009. 

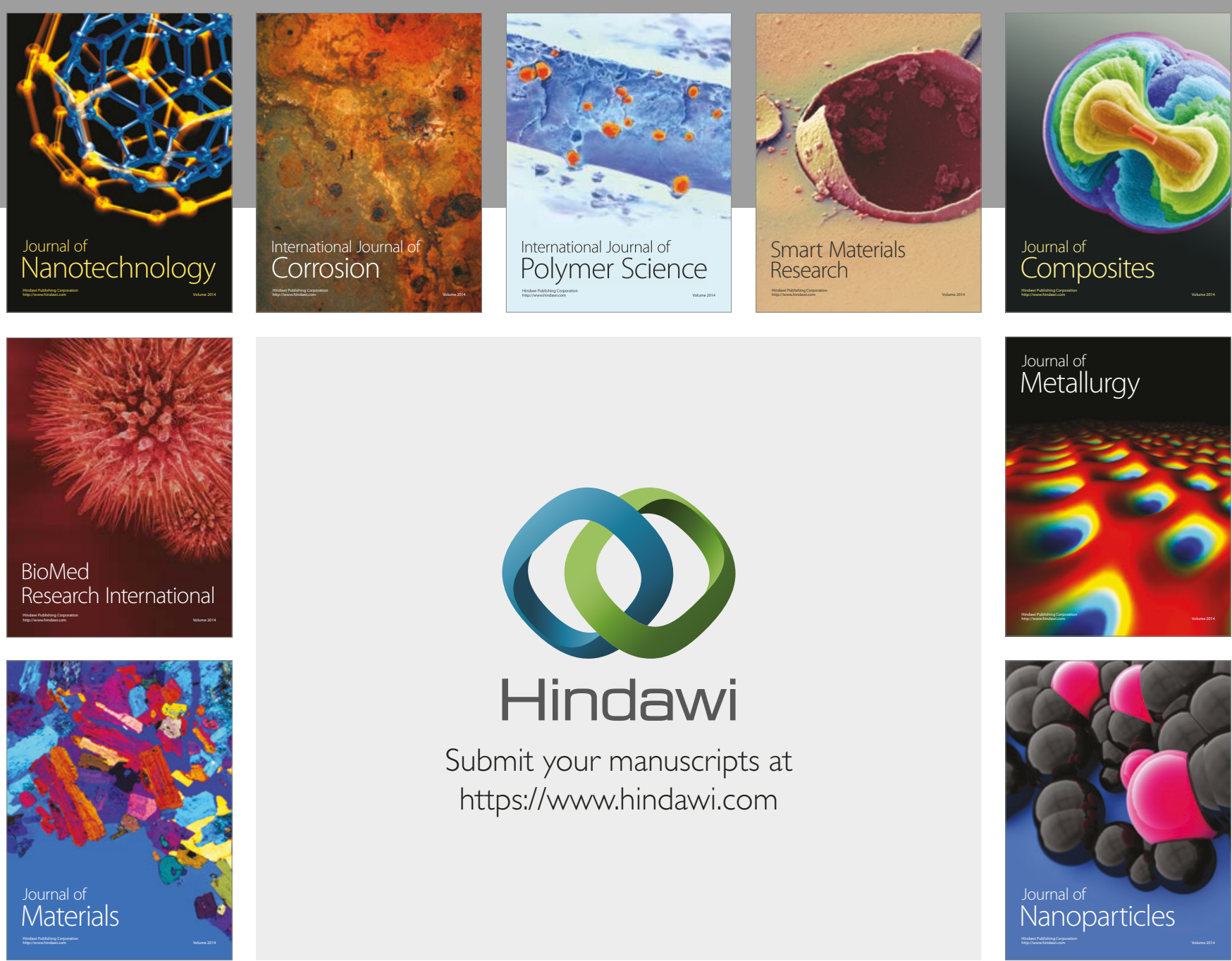

\section{Hindawi}

Submit your manuscripts at

https://www.hindawi.com
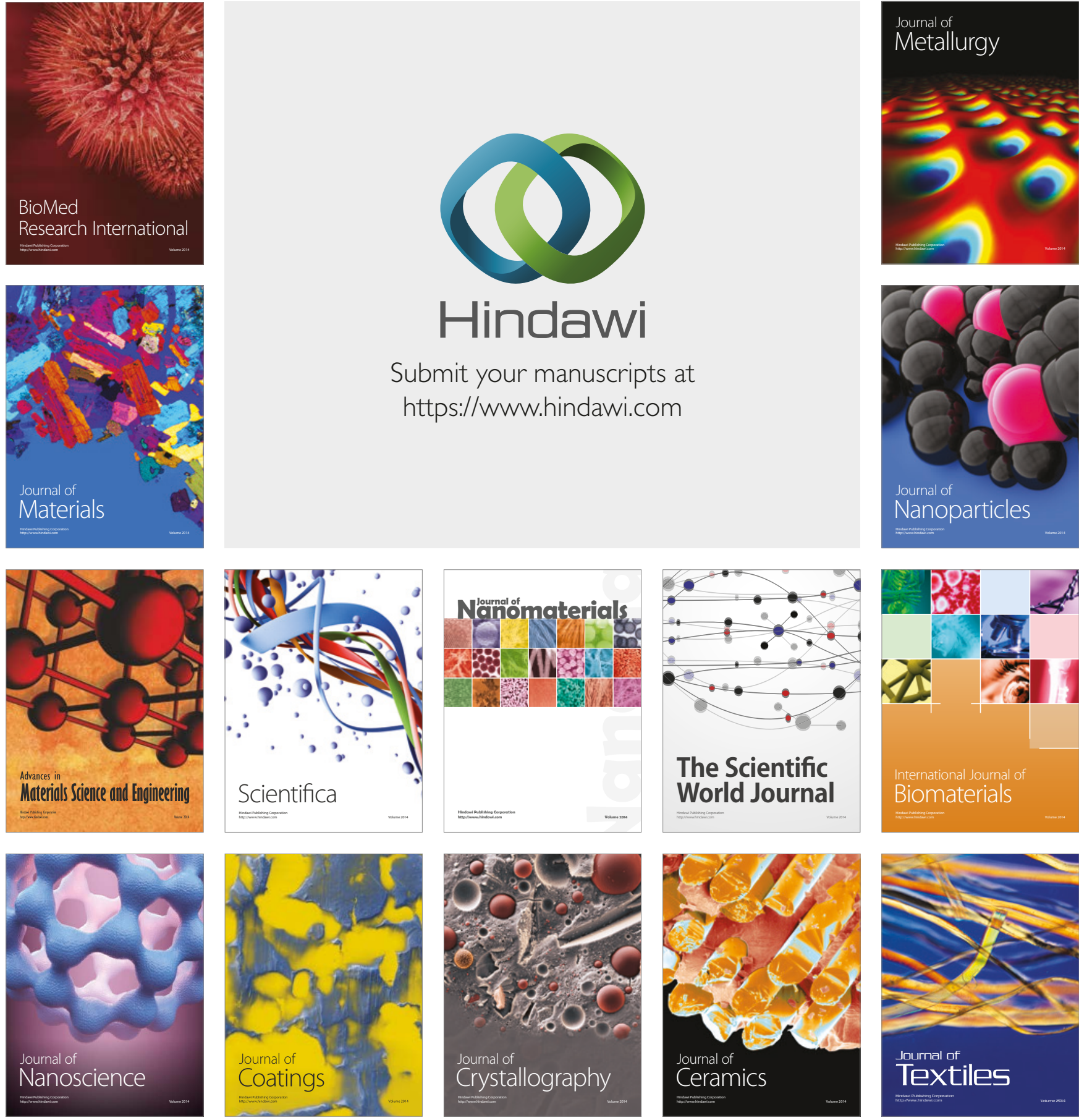

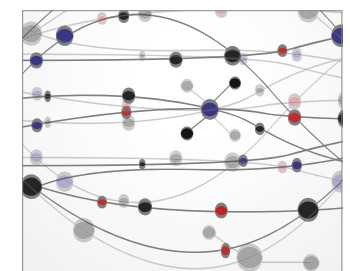

The Scientific World Journal
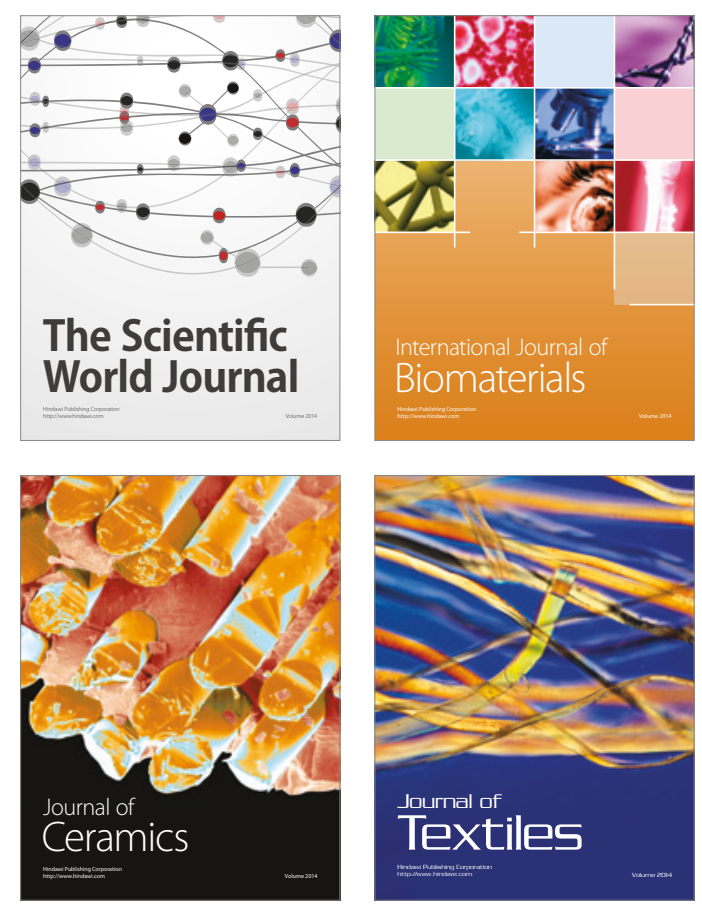